\title{
Nuck Kanal Hidroseli Hydrocele of the Canal of Nuck
}

\author{
Bartu Badak, Enver İhtiyar \\ Eskişehir Osmangazi Üniversitesi Tıp Fakültesi, Genel Cerrahi Anabilim Dalı, Eskişehir,Türkiye
}

Özet: Kadınlarda Nuck kanal hidroseli oldukça nadir olup, kız çocuklarında processus vaginalisin kapanma defekti sonucu ortaya çıkan, parietal peritonun Nuck kanalına invajinasyonu olarak tanımlanır. Bu yazımızda literatürde az sayıda olması nedenli sol kasıkta şişlik nedenli başvuran 37 yaşında bayan hasta sunuldu.

Anahtar Kelimeler: nuck kanal hidroseli, processus vaginalis, kapanma defekti

Badak B, İhtiyar E. 2019. Nuck Kanal Hidroseli, Osmangazi Tip Dergisi, 41(4): 421-424 Doi: 10.20515/otd.340115

Abstract: Hydrocele of the canal of Nuck is very rare in female population, that occurs because of the obliteration failure of processus vaginalis in girls, which characterized involvement of the parietal peritoneum into the canal of Nuck. In this writing a 37 year old female patient with left inguinal swelling presented, because of the shortage number of this case in literature search.

Keywords: hydrocele of canal of nuck, processus vaginalis, obliteration failure

Badak B, Ihtiyar E. 2019. Hydrocele of the Canal of Nuck, Osmangazi Journal of Medicine, 41(4):421-424 Doi: 10.20515/otd.340115 


\section{Giriş}

Bayanlarda inguinal kanal içerisine doğru round ligamanı ile birlikte intraabdominal peritoneal yapılar cep şeklinde ilerler ve labium majore yapışıllar. $\mathrm{Bu}$ oluşum erkeklerdeki processus vajinalisin karşılığıdır ve Nuck divertikülü adını alır. Yaşamın ilk yilında bu cep katlanarak aynen processus vaginaliste olduğu gibi kapanır. $\mathrm{Bu}$ kapanmada oluşacak bir defekt hidrosel veya herni ile sonuçlanmaktadır (1).

Nuck kanal kisti ilk kez 1650 y1lında Anton Nuck tarafından tanımlanmıştır (2). İnguinal kanalda șişlik meydana getirebilecek birçok faktörle karışması sebepli ve literatürde az sayıda bulunması sebepli bu yazımızda Nuck Kanal hidroselli bayan hastayı sunmayı, ayırıcı tanıya yardımcı olmayı ve literatüre katkıda bulunmayı amaçladık.

\section{Olgu}

37 yaşında bayan hasta sol kasıkta şişlik nedenli kliniğimize başvurdu. Anamnezinden bu şişliğin yaklaşık 5 aydır mevcut olduğu ve bu şişliği yok etmek için antibiyoterapi kullanımının mevcut olduğu öğrenildi. Hastanın özgeçmişinde herhangi bir özellik yoktu, sürekli kullandığı bir ilaç veya herhangi bir operasyon hikayesi bulunmamaktaydı. Ameliyat öncesi çalışılan laboratuvar değerlerinde herhangi bir bozukluk saptanmadı. Fizik muayenesinde ise sol kasık bölgesinde inguinal kanal üzerinde
SIAS (spina iliaca superior anterior)'a yakın bir bölgeden başlayıp sol labium majore kadar uzanan yaklaşık $8 \times 3 \quad \mathrm{~cm}$ 'lik semi-mobil oluşum ele gelmekteydi. Muayenede içeriğin daha çok sıvı olabileceği düşünüldü. Oluşumun içinde barsak ansı palpe edilmedi. Translüminasyon testi ile içerisinde sıvıdan başka yapı gözlemlenmedi. Valsalva ile belirginleşme göstermezken; inguinal kanala da redükte olmamaktaydı. Ciltte ekimoz, hiperemi, 1sı artışı gibi nekrozu düşündürebilecek bir bulgu yoktu. Etyolojiye yönelik bu bölgeye yönelik yapılan yüzeyel ultrasonografide "sol inguinal bölgede $8 \times 5 \times 8$ $\mathrm{cm}$ boyutunda içerisinde kalsifik odakların izlendiği, içerisinde septasyonların izlendiği kistik yer kaplayan oluşum" raporlanmas1 üzerine hasta elektif şartlarda operasyona hazırlandı. Sol inguinal bölgeden yapılan kesi ile anatomik katlar geçilip round ligamanı askiya alınarak yapılan eksplorasyonda inguinal kanaldan orijin aldığı görülen, labium majusa kadar uzanan kistik oluşum gözlemlendi (Şekil1). Künt ve keskin diseksiyonlarla bu oluşum total olarak eksize edildi (Şekil2). Yüksek ligasyonla defekt onarıld1. Ameliyat sonrası 1. günde oral alımı açılan hasta poliklinik ve pansuman kontrolü ile taburcu edildi. Histopatolojik inceleme sonucu kist duvarında düz kas lifleri bulunan küboidal epitelyum ile döşeli olması üzerine hastaya 'Nuck kanal hidroseli' tanısı kondu.

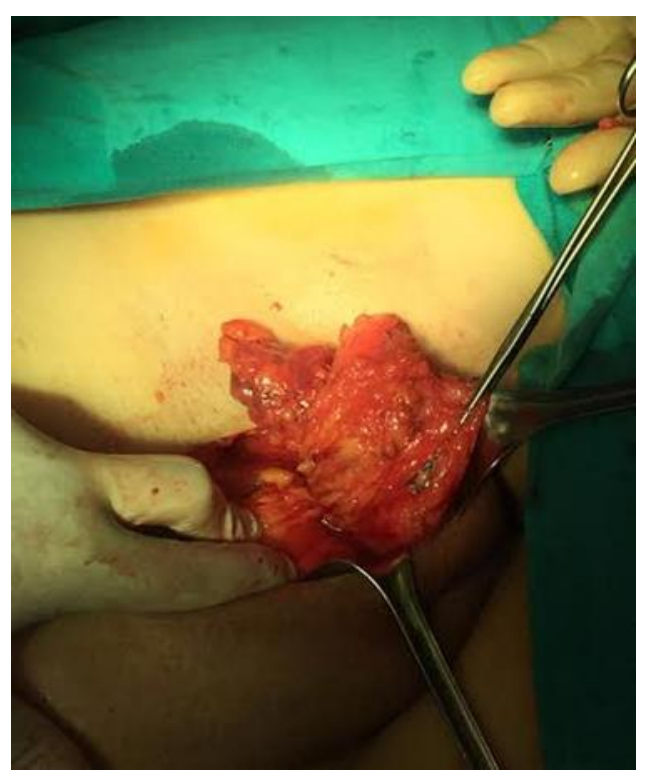


Resim 1. Eksplorasyon bulgusu

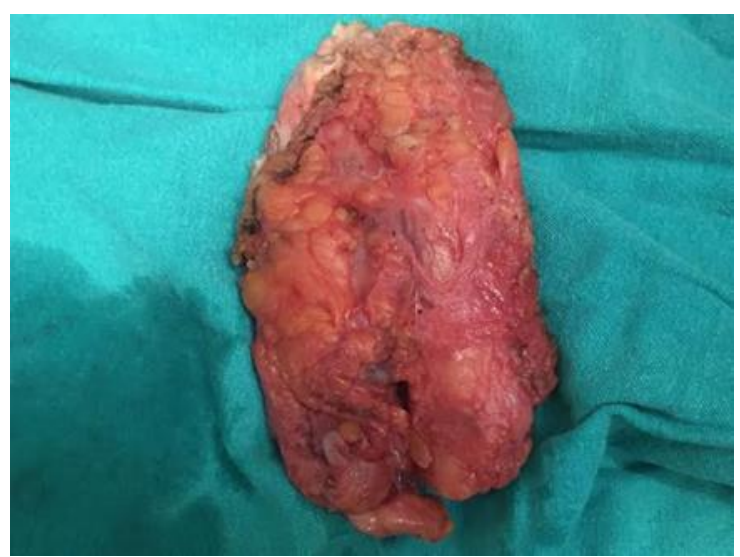

Resim 2. Eksize edilen materyal

\section{Tartışma}

Bayanlarda intraabdominal peritoneal yapilar cep şeklinde round ligamanı ile birlikte inguinal kanala doğru ilerlerler. Bu yapılara Nuck divertikülleri adı verilir ve erkeklerdeki pocessus vaginalisin karşılığıdırlar. Normal şartlarda yaşamın ilk yılında bu uzantılar fibröz kordonlara dönüşerek kapanırlar. Erkeklerde processus vaginaliste olduğu gibi bayanlarda da bu nuck divertiküllerinin kapanma defektleri; herni, hidrosel veya kist oluşumu ile sonuçlanırlar (1). Wei ve arkadaşları (3) 2002 yılına kadar olan olguları kapsayan çalışmalarında vaka sayısının yaklaşık 400 civarında olduğunu bildirmektedirler.

Kadın hidroselleri genellikle kendilerini kasık bölgesinde ele gelen ağrısız kitle imaj1 ile belli ederler. Bu bağlamda bu oluşumların hernilerden ve diğer yer kaplayan oluşumlardan (neoplaziler, abse, lenfadenopatiler...) ayırıcı tanısı önem arz etmektedir. Translüminasyon testi ve valsalva manevrası bizim vakamızda da olduğu gibi kullanılabilmektedir ancak retroperitoneal kitleler ve Nuck kanalına herniye olan over ve tubaların olduğu vakaların varlığı nedeniyle \%100 güvenilir değildirler. (4) Tanıda en çok kullanılan yöntem ultrasonografidir. Tipik olarak sosis şeklinde kistik oluşumlar görüntülenir. (5) Komplike olgularda manyetik rezonans (MR) ile görüntülemeden de yardım alınabilir. (5) Ancak kesin tanı her zaman histopatolojik inceleme sonucu konur. Kist duvarında düz kas dokuları bulunan mezotelyal karakterde tek katlı küboidal hücreler görülmesi tipiktir. (5) Bizim vakamızda da patolojik inceleme uyumlu idi.

\section{Sonuç}

Nuck kanal hidrosellerinin tedavisi cerrahidir. Kist aspirasyonunun tedavide yeri yoktur. Açık veya laparoskopik cerrahi seçenekleri mevcuttur (6). Sonuç olarak Nuck kanal hidrosellerinin inguinal kitle ile başvuran bayan hastalarda akılda tutulmasının faydalı olacağı görüşündeyiz. 


\section{KAYNAKLAR}

1. Frederic DM, Marek W, Guy H, Jose R. Female hydrocele of the canal of Nuck: Eur J Pediatr 2006; 165:193-194.

2. Khanna PC, Ponsky T, Zagol B, Lukish JR, Markle BM. Sonographic appearance of canal of Nuck hydrocele. Pediatr Radiol 2007; 37 (6): 603-606.

3. Wei BP, Castles L, Stewart KA. Hydrocele of the canal of Nuck. ANZ J Surg 2002; 72(8): 603-605.

4. McCune WS. Hydrocele of the canal of Nuck with large cystic retroperitoneal extension. Ann Surg 1948;127(4):750-3.

5. Park SJ, Lee HK, Hong HS, Kim HC, Kim DH, Park JS, et al. Hydrocele of the canal of Nuck in a girl: ultrasound and MR appearance. Br J Radiol 2004; 77(915):243-44.

6. Yen CF, Wang CJ, Lin SL, Chang PC, Lee CL, Soong YK. Laparoscopic closure of patent canal of Nuck for female indirect inguinal hernia. J Am Assoc Gynecol Laparosc 2001; 8(1):143-146. 